\title{
ANALISIS KINERJA PEMELIHARAAN BERDASARKAN SAFETY PERFORMANCE INDICATOR MENGGUNAKAN RELIABILITY MAPPING
}

\author{
Mufti Arifin \\ Prodi Teknik Penerbangan, Fakultas Teknologi Kedirgantaraan, \\ Universitas Dirgantara Marsekal Suryadarma \\ muftiarifin@gmail.com
}

\begin{abstract}
Abstrak- ICAO Annex 19 tentang Safety Management mensyaratkan pengukuran safety menggunakan Safety Performance Indicator (SPI). Parameter SPI ditetapkan oleh operator. Salah satu contoh adalah parameter maintenance (pemeliharaan) yang terkait accident atau incident. SPI maintenance terdiri dari Pilot Report, Dispatch Reliability, Deferred Maintenance (DMI), Service Difficulty Report, Air Turn Back, Rejected Take Off, dan Repeated Defect. Beberapa parameter SPI memiliki korelasi satu sama lain. Simulasi telah dilakukan menggunakan reliability mapping dengan berbagai skenario pemeliharaan untuk melihat hubungan antara parameter Deferred Maintenance Item, Repeated Defect, dan Technical Interruption yang digunakan pada perhitungan Dispatch Reliability. Analisis kinerja pemeliharaan juga disimulasikan dengan metode ini. Hasil simulasi memperlihatkan hubungan sebab akibat dua arah dan satu arah diantara ketiga parameter SPI. Kinerja pemeliharaan dapat diperkirakan dari reliability mapping terutama waktu yang diperlukan untuk penyelesaian defect dan kejadian berulang baik defect, $\mathrm{DMI}$, atau technical interruption.
\end{abstract}

Kata kunci : SPI, Pemeliharaan, Technical Interruption, DMI, Repeated Defect

\begin{abstract}
ICAO Annex 19 Safety Management required safety measurement using Safety Performance Indicator (SPI). SPI parameter determined by operator. One of example is maintenance parameter related with accident or incident. SPI maintenance consist of Pilot Report, Dispatch Reliability, Deferred Maintenance (DMI), Service Difficulty Report, Air Turn Back, Rejected Take Off, and Repeated Defect. Some of SPI parameters have correlations. Simulation using reliability mapping with varies maintenance scenario to see correlation between Deferred Maintenance Item, Repeated Defect, and Technical Interruption which is used for Dispatch Reliability calculation has been done. Maintenance performance analysis also simulated with this method. The result shows cause effect correlation in two and one way between three SPI parameters. Maintenance performance could be predicted using reliability mapping mainly for time needed for defect rectification and repeated defect, repeated DMI, or repeated technical interruption
\end{abstract}

Keywords: SPI, maintenance, Technical Interruption, DMI, Repeated Defect

\section{PENDAHULUAN}

ICAO Annex 19(1) tentang Safety Management mendefiniskan safety (keselamatan) adalah keadaan dimana resiko yang terkait aktivitas dunia penerbangan (aviation), berhubungan atau sebagai dukungan operasional pesawat, telah dikurangi dan dikendalikan pada tingkat yang dapat diterima. Safety performance didefinisikan sebagai pencapaian safety dari penyedia layanan sesuai target yang telah ditetapkan dan sesuai safety performance indicator. Definisi ini menyiratkan pengukuran yang kompleks, tidak hanya focus pada kejadian incident atau accident, tetapi juga kondisi hazard yang berpotensi mengakibatkan incident atau accident.

Safety Performance Indicator (SPI) adalah database parameter safety yang digunakan untuk memonitor dan menilai performa keselamatan. Safety performance target adalah perencanaan atau tujuan yang ingin dicapai dari SPI dalam periode waktu tertentu.

Indikator pada SPI secara garis besar terdiri dari Lagging Indicator, yaitu ukuran kejadian yang telah terjadi 
termasuk yang telah dicoba untuk dicegah dan Leading Indicator, yaitu ukuran sesuatu yang memiliki potensi menjadi atau berkontribusi pada akibat negatif di kemudian hari (negative indicator) dan sesuatu yang berkontribusi terhadap keselamatan (positive indicator). ${ }^{(2)}$

Parameter yang digunakan dalam SPI ditetapkan oleh masing-masing operator (maskapai). SPI dapat dibagi menjadi tiga bagian utama yaitu Indikator terkait sistem, indicator terkait operasional, dan indicator terkait faktor dari luar. Salah satu bagian dari indicator operasional yaitu kegiatan pemeliharaan yang memiliki hubungan dengan incident atau accident.

Matriks yang masuk ke dalam SPI operasional pemeliharaan diantaranya adalah Pilot Reports (PIREPS), Deferred Maintenance Items (DMI), Air turn back, Service Difficulty Report (SDR), Dispatch Reliability yang terdiri dari delay lebih dari 15 menit, pembatalan penerbangan (cancellation), dan Rejected Take Off (RTO) $^{(2)}$.

PIREPS adalah laporan Penerbang terkait defect (kerusakan, kekurangan, atau gangguan) pada pesawat yang harus ditindaklanjuti oleh bagian pemeliharaan. DMI merupakan penundaan kegiatan pemeliharaan karena berbagai sebab dengan tetap mempertahankan kelaikan udara pesawat berdasarkan Minimum Equipment List (MEL) yang telah ditetapkan. MEL dibuat agar pesawat tetap dapat dioperasikan meskipun terdapat peralatan yang tidak bekerja atau tidak berfungsi tetapi masih dalam tingkat safety yang dapat diterima ${ }^{(3)}$.

SDR merupakan laporan operator kepada Authority (Regulator) jika terjadi kegagalan atau defect sesuai Civil Aviation Safety Regulation CASR $121.703^{(4)}$. Dispatch Reliability adalah ukuran efektifitas keseluruhan dari operasional maskapai penerbangan terkait on-time departure ${ }^{(5)}$. Keberangkatan dinyatakan on-time jika tidak terjadi delay atau gangguan lainnya (interruptions) dari jadwal yang telah ditetapkan.

Delay dihitung jika keberangkatan terlambat lebih dari 15 menit dari jadwal. Delay merupakan salah satu technical interruptions selain air turn back, (pesawat yang sudah mengudara kembali mendarat di bandara keberangkatan), rejected take off (pesawat membatalkan take off), diversion (pesawat yang sudah mengudara terpaksa mengalihkan pendaratan), return to apron (pesawat kembali ke apron sebelum take off), dan AOG (aircraft on ground, pesawat tidak laik untuk terbang). Berbagai kejadian tersebut merupakan technical interruption jika disebabkan alasan teknis dan memerlukan tindakan pemeliharaan.

PIREPS pada defect yang sama dapat berulang (repeated atau repetitive defect). Repeated defect terjadi jika defect yang sama berulang lebih dari dua kali dalam jangka waktu 30 hari. ${ }^{(6)}$ Edaran keselamatan yang dikeluarkan Perhubungan Udara mewajibkan repeated defect dimonitor menggunakan DMI. Hal ini untuk mencegah defect tidak terpantau dan terjadi terus menerus. Jika DMI yang memiliki batasan hari tidak terselesaikan, maka pesawat akan dinyatakan AOG. Repeated defect juga bisa menjadi parameter dari SPI pemeliharaan $^{(7)}$.

Terlihat ada kaitan antara SPI PIREPS, Repeated Defect, Dispatch Reliability, Technical Interruptions, dan DMI. Penelitian untuk melihat hubungan secara keseluruhan antara technical intteruptions (return to apron, air turn back, dan rejected take off) dan repeated defect dengan studi kasus data pemeliharaan selama satu tahun telah dilakukan. Hasil analisis menunjukkan terdapat korelasi moderat secara keseluruhan (berdasarkan jumlah tanpa melihat subsistem). Korelasi kuat terjadi pada beberapa sub system (Sub ATA chapter) (8).

Perbandingan repetitive defect dan DMI juga telah dilakukan dengan hasil 
korelasi kuat untuk beberapa subsistem yang menjadi studi kasus, tetapi korelasi secara keseluruhan lemah mengingat DMI tidak selalu karena adanya repeated defect. $^{(9)}$

Analisis lebih detil dapat dilakukan untuk melihat korelasi antar ketiga parameter SPI tersebut. Korelasi antar parameter diperkirakan dapat digunakan sebagai indikator kinerja pemeliharaan selain sebagai SPI. Salah satu metode analisis yang dapat digunakan adalah reliability mapping ${ }^{(10)}$ seperti pada Gambar 1.

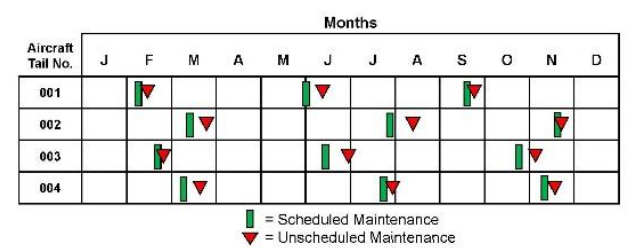

Gambar 1. Contoh Reliability Mapping

Metode ini praktis digunakan untuk melihat korelasi antara pemeliharaan terjadwal dan pemeliharaan tidak terjadwal. Studi kasus yang telah dilakukan juga menunjukkan efektivitas metode ini ${ }^{(11)}$.

Penelitian ini mensimulasikan reliability mapping dari DMI, technical innterruptions, dan repeated defect. Analisis kinerja bagian maintenance (pemeliharaan) dilakukan untuk berbagai skenario simulasi.

\section{METODE PENELITIAN}

Penelitian dilakukan dengan mensimulasikan kejadian technical intteruptions, defect, dan DMI secara grafis sesuai metode reliability mapping.

\subsection{Skenario simulasi}

Simulasi dilakukan dengan berbagai kemungkinan yang terjadi agar mendekati kondisi actual operasional dan pemeliharaan.

\subsection{Pesawat}

Simulasi dilakukan tidak khusus menggunakan suatu tipe pesawat tertentu agar hasilnya dapat digunakan secara umum. Reliability mapping dari berbagai indikator disimulasikan untuk satu sub system atau defect yang sama atau terkait. Simulasi dilakukan dengan satu pesawat (serial number atau tail number) yang sama dan secara armada (terdiri dari beberapa pesawat).

\section{HASIL DAN PEMBAHASAN}

\subsection{Technical Intteruptions dan Repeated Defect}

Simulasi awal menggunakan satu pesawat dengan satu jenis defect. Defect dilambangkan dengan warna biru, repeated defect $(\mathrm{RD})$ ditunjukkan dengan warna biru berulang. Technical interruption (TI) dilambangkan dengan warna merah, DAYS menyatakan hari, dan AC adalah pesawat.

Simulasi 1:

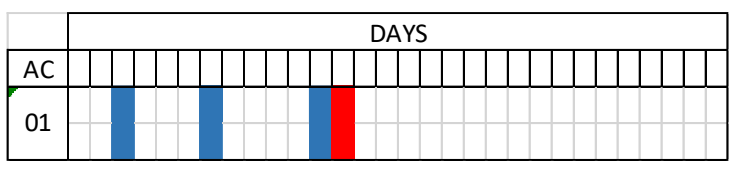

Gambar 2. Simulasi 1

Simulasi seperti pada Gambar 2 menunjukkan terjadi tiga kali defect (RD) yang diikuti oleh TI. Kondisi tersebut menunjukkan tindakan pemeliharaan tidak dapat menyelesaikan defect dan berakibat TI. Defect tidak terjadi lagi setelah TI menunjukkan pemeliharaan berhasil menyelesaikan RD setelah $\mathrm{TI}$.

Simulasi 2

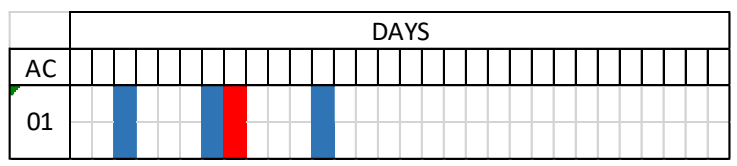

Gambar 3. Simulasi 2 
diselesaikan tanpa terjadi $\mathrm{TI}$.

Simulasi kedua menunjukkan bahwa terjadi $\mathrm{RD}$ yang diikuti atau bersamaan dengan $\mathrm{TI}$ yang kemudian diikuti dengan defect setelah beberapa hari kemudian. Kondisi ini berarti pemeliharaan tidak berhasil menyelesaikan RD meskipun sudah sampai terjadi $\mathrm{TI}$.

Simulasi 3 :

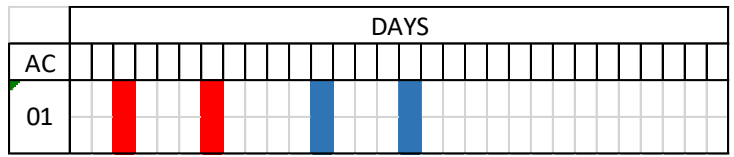

Gambar 4. Simulasi 3

Simulasi ketiga memperlihatkan terjadi dua kali TI tanpa didahului RD. Setiap TI sendiri merupakan defect. Terjadinya TI berulang pada subsistem yang sama menunjukkan tindakan yang tidak efektif atau tidak menyelesaikan defect. Kinerja meintenance semakin turun jika diikuti dengan RD.

Simulasi 4 :

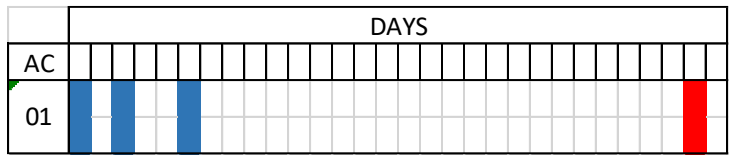

Gambar 5. Simulasi 4

Gambar 5 menunjukkan RD memiliki jarak yang cukup jauh dengan $\mathrm{TI}$. Hal ini dapat diartikan TI dan RD tidak terkait meskipun pada subsistem yang sama. Tentu saja kriteria jarak ini relatif tergantung subsistem yang dianalisis.

Simulasi 5 :

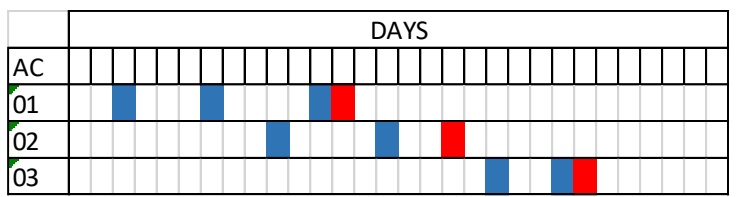

Gambar 6 Simulasi 5

Simulasi 5 dengan beberapa pesawat memperlihatkan trend atau pola bahwa RD terselesaikan setelah terjadi TI. Tren atau pola dengan kinerja pemeliharaan seperti ini perlu diperbaiki sehingga RD bisa
Pada simulasi fleet di Gambar 7 tidak terdapat tren atau pola terkait kinerja pemeliharaan.

Simulasi 6

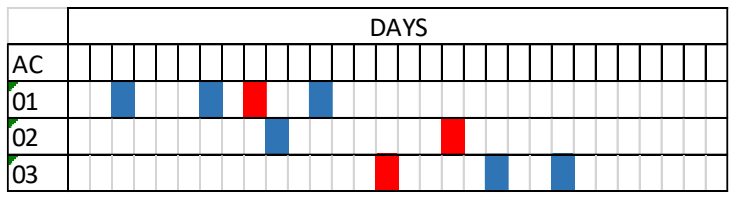

Gambar 7. Simulasi 6

\subsection{Repeated Defect dan DMI}

Awal dari DMI (DMI open) pada simulasi dinyatakan dengan warna kuning sedangkan warna hijau menunjukkan DMI telah diselesaikan (DMI closed). Warna biru adalah RD.

Simulasi 7 :

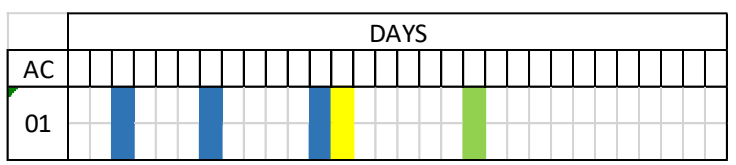

Gambar 8. Simulasi 7

Pada Gambar 8 terlihat RD diikuti dengan membuka DMI, dan DMI diselesaikan beberapa hari kemudian. Hal ini sesuai dengan edaran keselamatan yang dikeluarkan regulator. Kinerja pemeliharaan sudah sesuai edaran keselamatan.

Simulasi 8:

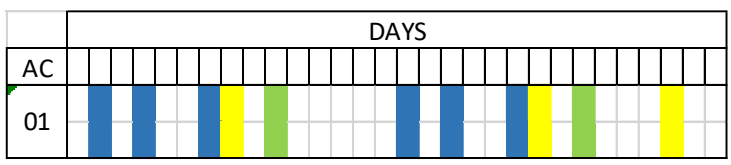

Gambar 9. Simulasi 8

Simulasi menunjukkan terjadi RD diikuti DMI open dan DMI open, namun beberapa hari kemudian, terjadi RD dengan defect yang sama. RD tentu saja harus diikuti dengan DMI open dan DMI closed. Pada kasus seperti ini, tidak hanya terjadi RD 
tetapi juga terjadi repeated DMI. Hal ini terjadi karena pemeliharaan yang dilakukan saat DMI closed pertama tidak menyelesaikan masalah. Trouble shooting yang tidak tepat sehingga root cause (akar permasalahan) belum terselesaikan.

Simulasi 9 :

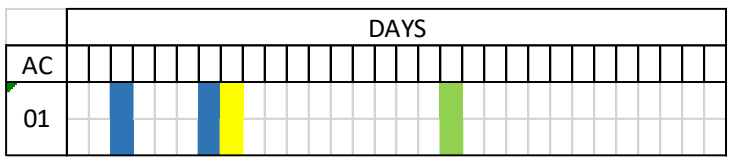

Gambar 10. Simulasi 9

Gambar 10 memperlihatkan DMI open dilakukan saat belum terjadi RD, saat defect baru terjadi dua kali. Kinerja pemeliharaan lebih baik karena mencegah $\mathrm{RD}$ terjadi dengan membuka DMI.

Simulasi 10

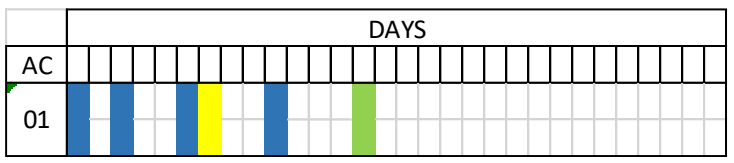

Gambar 11. Simulasi 10

Simulasi 10 memiliki RD diikuti open DMI. DMI belum diselesaikan tetapi terjadi defect (PIREP) setelah DMI open. Kondisi ini seharusnya tidak terjadi karena DMI open berarti defect telah diketahui oleh bagian pemeliharaan dan tidak perlu dilaporkan oleh pilot. Kasus ini bisa terjadi jika Pilot tidak melihat DMI Open atau DMI open yang dibuka tidak cukup jelas.

Simulasi 11

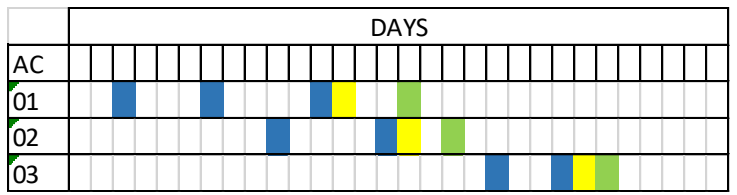

Gambar 12. Simulasi 11

Pada simulasi dengan beberapa pesawat, pola tindakan pemeliharaan terhadap defect berulang bisa terlihat. Pada pesawat 01 DMl open setelah RD, tetapi pada pesawat 02 dan $03 \mathrm{DMI}$ open sebelum terjadi RD. Kinerja pemeliharaan juga terlihat dari jumlah hari yang diperlukan untuk menyelesaikan DMI.
Simulasi 12:

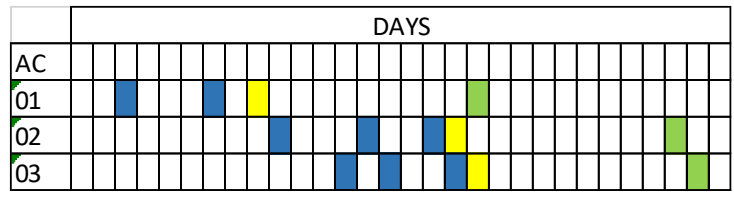

Gambar 13. Simulasi 12

Pada simulasi ini, terlihat pola penyelesaian DMI memakan waktu lama. Kinerja pemeliharaan dari sisi penyelesaian DMI lebih rendah daripada pada simulasi 11, meskipun kinerja pemeliharaan dalam membuka DMI terhadap adanya $\mathrm{RD}$ mirip.

\subsection{Technical Interruption dan DMI}

TI dilambangkan dengan warna merah, awal dari DMI (DMI open) dinyatakan dengan warna kuning sedangkan warna hijau menunjukkan DMI telah diselesaikan (DMl closed).

Simulasi 13:

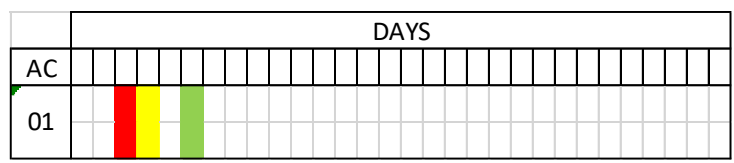

Gambar 14. Simulasi 13

Pada Gambar 14 terlihat terjadi TI diikuti DMI open dan DMI closed 2 hari kemudian. Kondisi ini terjadi jika defect yang mengakibatkan TI dapat ditunda penyelesaiannya melalui open DMI agar pesawat bisa tetap beroperasi.

Simulasi 14:

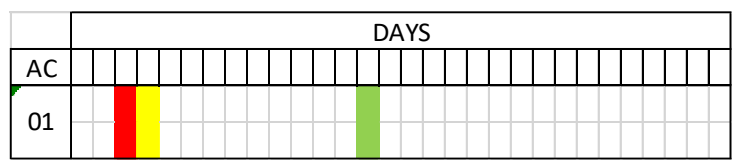

Gambar 15. Simulasi 14

Pada kasus yang mirip dengan simulasi 13, kinerja pemeliharaan pada simulasi 14 lebih buruk karena DMI diselesaikan pada 
periode yang lebih lama (10 hari).

Simulasi 15

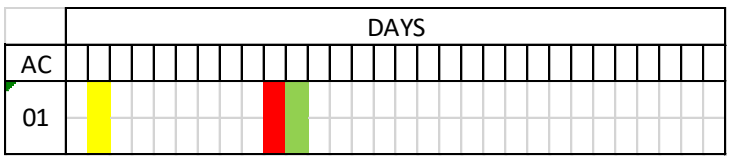

Gambar 16. Simulasi 15

Simulasi 15 diawali dengan DMI open, terjadi TI beberapa hari kemudian, diikuti dengan DMI closed. DMI open bisa terjadi akibat adanya RD atau defect tunggal yang jika penyelesaiannya tidak ditunda, maka pesawat AOG.

Pada simulasi ini, terjadi TI sebelum DMI diselesaikan. Defect yang terjadi telah berkembang menjadi defect yang mengakibatkan TI. Jika kinerja pemeliharaan lebih baik dalam bentuk penyelesaian DMI lebih cepat, terjadinya $\mathrm{TI}$ bisa dicegah.

Simulasi 16

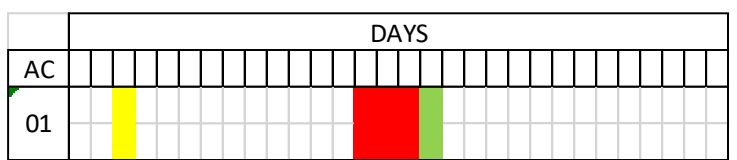

Gambar 17. Simulasi 16

Simulasi 16 mirip dengan simulasi 15 dengan penyelesaian DMl yang lebih lama, sehingga pesawat AOG selama beberapa hari. AOG merupakan salah satu bentuk TI. Pada kasus ini, kinerja pemeliharaan yang tidak dapat menyelesaikan DMI sebelum waktunya habis mengakibatkan TI.

Simulasi 17

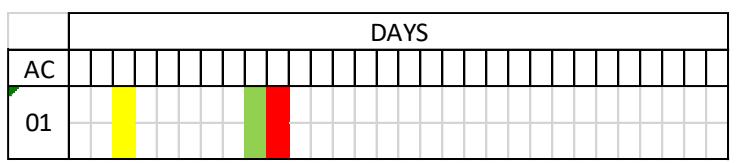

Gambar 18. Simulasi 17

Simulasi pada Gambar 18 menunjukkan DMI open, DMI open, kemudian diikuti oleh $\mathrm{TI}$. TI setelah penyelesaian DMI bisa diartikan tindakan pemeliharaan saat menyelesaikan DMI (closing DMI) malah mengakibatkan TI. Kesalahan pemeliharaan merupakan salah satu penyebab kasus seperti ini.

Simulasi 18

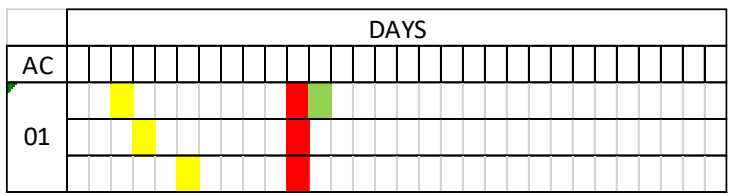

Gambar 19. Simulasi 18

DMI open tidak selalu tunggal. Satu pesawat dapat mengalami beberapa defect bersamaan sehingga memiliki beberapa DMI open. Jika DMI open terjadi pada beberapa subsistem terkait, maka bisa mengakibatkan $\mathrm{TI}$.

Simulasi 19

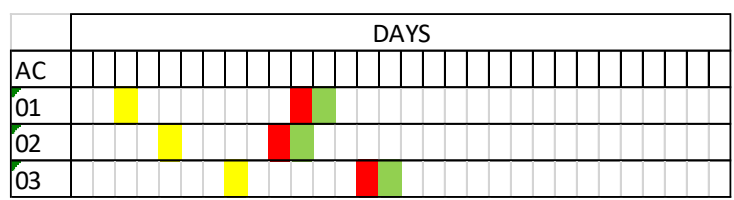

Gambar 20. Simulasi 19

Pada simulasi dengan beberapa pesawat, terlihat pola kinerja pemeliharaan yang rendah karena DMI diselesaikan setelah terjadi TI. Tindakan pemeliharaan kurang aktif sehingga tindakan penyelesaian DMI dilakukan dipicu oleh TI.

Simulasi 20

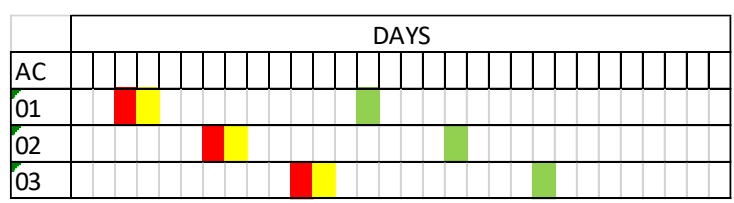

Gambar 21. Simulasi 20

Simulasi 21 


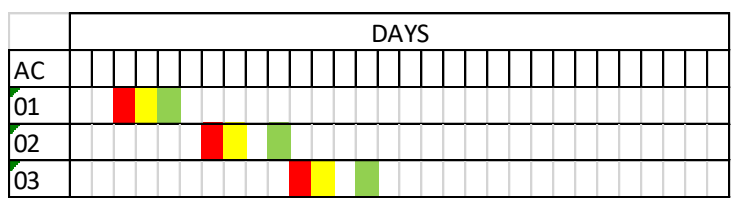

Gambar 22. Simulasi 21

Simulasi 20 dan 21 menunjukkan pola kinerja pemeliharaan terhadap DMI open seperti pada simulasi 11 dan 12. Kinerja pemeliharaan lebih baik ditunjukkan dengan waktu penyelesaian DMI lebih cepat.

\subsection{Analisis}

Simulasi dalam bentuk reliability mapping dapat menunjukkan hubungan antara dua dari tiga parameter SPI. Urutan munculnya warna dapat digunakan untuk menunjukkan hubungan sebab akibat. Hubungan sebab akibat RD dan TI bisa terjadi dalam dua arah, karena setiap $\mathrm{TI}$ adalah defect. Pada RD dan DMI terjadi hubungan sebab akibat satu arah sesuai Edaran Keselamatan. Hubungan sebab akibat dua arah juga dapat terjadi pada TI dan DMI.

Kinerja pemeliharaan dapat langsung diketahui dari banyaknya event baik defect, DMI dan TI. Pesawat dalam kondisi terbaik terlihat jika tidak terdapat warna satu warna pun pada reliability mapping. Semakin banyak warna berarti semakin banyak gangguan pada pesawat yang memerlukan tindakan pemeliharaan.

Kinerja pemeliharaan lebih terlihat jika terbentuk pola pada mapping dari beberapa pesawat. Bentuk tren atau pola dapat diartikan kinerja pemeliharaan berpengaruh ke semua pesawat.

Jarak antar warna pada reliability mapping DMI juga menunjukkan kinerja pemeliharaan. Semakin pendek jarak DMI open dan closed, kinerja pemeliharaan semakin baik.

Kinerja pemeliharaan semakin buruk jika tidak hanya terjadi repeated defect tetapi juga terjadi repeated technical interruption dan atau repeated DMI.

Analisis dari 21 simulasi yang telah dilakukan dapat dikembangkan dengan simulasi lainnya dan perlu diuji dengan berbagai studi kasus menggunakan data actual dari operasional dan pemeliharaan.

\section{KESIMPULAN}

Kesimpulan yang dapat ditarik dari pembahasan yang telah dilakukan adalah :

1. Reliability mapping dapat menunjukkan hubungan antar ketiga parameter SPI.

2. Kinerja pemeliharaan dapat dianalisis dari waktu yang dibutuhkan untuk penyelesaian defect baik dalam bentuk Repeated Defect, DMI, maupun Technical Interruption.

3. Reliability mapping dari beberapa pesawat dapat menghasilkan pola yang menunjukkan kinerja pemeliharaan.

\section{DAFTAR PUSTAKA}

1. __ 2016. Safety Management. Annex $192^{\text {nd }}$ edition. International Civil Aviation Organization. Canada.

2. __, 2013. Measuring Safety Performance Guidelines for Service Provider. Safety Management International Collaboration Group.

3. ___ 2005. Getting to Grips with MMEL and MEL. Flight Operations Support and Services. Airbus. France

4. _ _ 2017. CASR part 121, Certification and Operating Requirement: Domestic, Flag, and Supplemental Air Carrier. Amendment 12. Ministry of Transportation Republic of Indonesia.

5. Kinnison, Harry A. 2004. Aviation Maintenance Management. McGrawHill. New York.

6. _, 2007. Safety Circular. AU/0649/DSKU/03/2007. Repetitive Discrepancy Maintenance Items. Direktorat Jenderal Perhubungan Udara, Departemen Perhubungan. 
7. __, 2012. Implementation Guide Aviation Program Performance Indicators (METRICS). US Department of Energy.

8. Putri, Luh Putu J. 2020. Analisis Safety Performance Indicator dari Technical Interruption dan Repetitive Problem Pada Pesawat ATR72. Tugas Akhir. Fakultas Teknologi Kedirgantaraan. Universitas Dirgantara Marsekal Suryadarma. Jakarta

9. Devia, Marissa N. 2020. Analisis Safety Performance Indicator dari Deferred Maintenance Item dan Repetitive Problem Pada Pesawat ATR72. Tugas Akhir. Fakultas Teknologi Kedirgantaraan. Universitas Dirgantara Marsekal Suryadarma. Jakarta.

10. Carrol, Thomas. 2015. Reliability Mapping Charting the way from Surveillance to Success. Hongkong.

11. Arifin, M., Kusumalestari, A. S., Anwar, A. N. 2018. Penggunaan Reliability Mapping pada Evaluasi Schedule Maintenance dan Unschedule Maintenance. Jurnal Teknologi Kedirgantaraan. Vol 3 No 2. Jakarta. 
